\title{
Microstructure and Residual Stresses in a Friction Stir Welded Butt Joint of as-cast ZK60 Alloy Containing Rare Earths
}

\author{
Erenilton Pereira da Silva ${ }^{*}$, Verona Biancardi Oliveira ${ }^{b}$, Victor Ferrinho Pereira ${ }^{c}$, Omar Maluf $^{\prime}$, \\ Ricardo Henrique Buzolin ${ }^{a}$, Haroldo Cavalcanti Pinto ${ }^{a}$ \\ ${ }^{a}$ Department of Materials Engineering, Engineering School of São Carlos, University of São Paulo, \\ São Carlos, SP, Brazil \\ ${ }^{b}$ Department of Materials, Polytecnic Institute, University of Rio de Janeiro State, \\ Nova Friburgo, RJ, Brazil \\ ${ }^{c}$ Brazilian Nanotechnology National Laboratory, Campinas, SP, Brazil \\ ${ }^{d}$ Faculty of Technology of Sertãozinho - FATEC, Sertãozinho, SP, Brazil
}

Received: December 19, 2016; Revised: February 11, 2017; Accepted: April 04, 2017.

The effect of a travel speed of $200 \mathrm{~mm} / \mathrm{min}$ as well as a tool rotational speed of $1200 \mathrm{rpm}$ on butt joint quality of friction stir welding (FSW) ZK60 magnesium casting alloy containing 1.5 wt.\% rare earths (ZK60-1.5RE) was investigated to determine microstructure and residual stresses. FSW results in the generation of heterogeneous metallurgical structures consisting of the base material (BM), stirred zone (SZ) and thermo-mechanical affected zone (TMAZ). The stirring action also produced a non-uniform distribution and segregation of intermetalics. The transversal distribution of the longitudinal welding stresses exhibits a "M-like" shape with mostly tensile stresses under the shoulder region and only one compressive stress peak in the advancing side of the SZ and TMAZ. It could be demonstrated that FSW of ZK60-1.5RE alloy was successful in the welding conditions applied during the present work.

Keywords: ZK60 alloy; rare-earth elements; friction stir welding; microstructure; residual stress

\section{Introduction}

A good combination of strength and ductility has been reported for the ZK60 magnesium alloy that represents an important matrix for the development of innovative light materials to be used in structural applications ${ }^{1}$ due to its highest specific strength among the commercial magnesium alloys. The effect of rare earth (RE) additions on the enhancement of strength and ductility has been investigated ${ }^{2,3}$. RE elements in addition to the Mg-Zn-Zr system ${ }^{4}$, such as in the ZE41 alloy $^{5}$, improved the castability and elevated temperature strength. Mg alloys possess low sublimation temperature, high thermal expansion coefficient and hot cracking susceptibility induced by intermetallic particles ${ }^{6}$ with a low melting point, which impose challenges to conventional fusion welding. Because friction stir welding (FSW) is a solid-state welding process $^{7}$, it cannot only overcome these problems related to conventional fusion welding, but also reduces distortion and residual stresses. The addition of RE elements to $\mathrm{Mg}$ alloys can contribute to a better weldability by forming higher melting point intermetallic compounds. The present investigation is to study the feasibility of the friction stir welding of cast ZK60 alloy with 1.5 wt.\% addition of mischmetal by evaluating the microstructure and the residual stress of butt joints as welded.

* e-mail: erenilton.silva@sc.usp.br

\section{Experimental}

\subsection{Materials and casting procedures}

In the present study, as-cast ZK60 alloy with $1.5 \mathrm{wt} \%$ addition of mischmetal (55\% Ce, 24\% La, 15\% Nd, 4\% Pr) was prepared by melting under mechanical stirring in the semi-solid state in an electric resistance furnace. For the manufacture of the alloy were put inside a crucible made of 1020 steel with the following materials in the form of solid blocks: pure Mg, electrolytic Zinc, Zirmax (nominally Mg33 wt.\%Zr) and mischmetal. The atmospheric control was performed as follows: after closing the furnace and before turning on the resistances, the vacuum pump is operated until the pressure of -0.45 to -0.6 bar when argon is then introduced until the pressure reaches $0 \mathrm{bar}$; the pump remains powered on during the whole process and the argon flow rate is controlled between $2-41 / \mathrm{min}$. The internal pressure was maintained between $-0,15$ bar and $-0,3$ bar, to prevent material loss by evaporation. During heating a mixer was introduced at $760{ }^{\circ} \mathrm{C}$ into the melt at approximately $600 \mathrm{rpm}$ and removed only at the end of the process; the maximum temperature was $820^{\circ} \mathrm{C}$ and at 15 minutes; a plateau was adopted until all materials had dissolved, and then the temperature was lowered to a minimum temperature of $650^{\circ} \mathrm{C}$ (above the liquids temperature). Next a new plateau of 15 minutes was used, enough to homogenize 
the temperature. Subsequently, the crucible was taken out of the furnace and then rapidly dropped into cold water $\left(25^{\circ} \mathrm{C}\right)$ with a crosshead speed of $100 \mathrm{~mm} / \mathrm{min}$.

\subsection{Experimental FSW setup}

Plates of $5.5 \mathrm{~mm}$ thick, $70 \mathrm{~mm}$ wide and $220 \mathrm{~mm}$ long were extracted from the ZK60-1.5RE ingots. They were then machined and put in to the friction stir welding. A RM1 FSW machine was employed for this process. The tool used for this process was made of $120 \mathrm{WV} 4$ tool steel with a shoulder of $18 \mathrm{~mm}$ diameter with a conical pin, $6 \mathrm{~mm}$ major diameter, 5 $\mathrm{mm}$ long and $30^{\circ}$ opening angle. It was tilted at $2^{\circ}$ to provide compressive force to the stirred weld zone. A tool rotational speed of $1200 \mathrm{rpm}$ and a travel speed of $200 \mathrm{~mm} / \mathrm{min}$ were applied to ensure full penetration. The normal force was setto $11.7 \mathrm{kN}$. The butt joints were cooled to room temperature without using shielding gas.

After welding, a transversal line profile of the longitudinal residual stresses was measured on the top side of the joints using the $\sin ^{2} \psi$ method ${ }^{9}$ by X-ray diffraction with a Panalytical MRD-XL diffractometer operating at $40 \mathrm{kV}$ and $40 \mathrm{~mA}$. A Co-KaX-ray beam with $\Lambda=0.1789 \mathrm{~nm}$ and diffraction lines from $\{103\},\{112\}$ and $\{201\}$ lattice planes were used for the analysis. The $\{103\},\{112\}$ and $\{201\}$ diffraction lines of $\mathrm{Mg}$ were measured at 10 (ten) different tilt angles q, covering a $\sin ^{2} \psi$-range from 0 up to 0.9 . The stress determination was accomplished by averaging the $\sin ^{2} \psi$ distributions of the three diffraction lines over their respective multiplicities. The diffraction elastic constants (DEC) for each diffraction line were calculated based on the Eshelby-Kroener's approach ${ }^{10}$. A beam of $2 \mathrm{~mm}$ x $2 \mathrm{~mm}$ was used with $15 \mathrm{~mm}$ wobbling along the welding direction. The residual stresses were analysed for 25 points symmetrically distributed with respect to the weld centreline and covering $72 \mathrm{~mm}$ along the transverse welding direction.

Samples for the metallographic examination were cut transversally to the welding direction. The samples were mounted and then wet grounded with successively finer grades of silicon carbide papers, followed by mechanical polishing using 6, 3 and $1 \mu \mathrm{m}$ diamond paste as the lubricant on polishing clothes. Subsequently, the images were collected using the optical microscope ZEISS AXIO SCOPE.A1. Specimens for scanning electron microscope (SEM) and electron backscattered diffraction (EBSD) examinations were polished mechanically with silica-free water solution. SEM and EBSD examinations were performed in a field emission JEOL JSM $6500 \mathrm{~F}$ microscope operating at $15 \mathrm{kV}$ and a step size of $70 \mathrm{~nm}$. An EBSD analysis was carried out using TSL-OIM software.

\section{Results and Discussion}

\subsection{Macrostructure}

The macrograph of the cross-section of the friction stir welded ZK60-RE casting alloy at the travel speed of 200 $\mathrm{mm} / \mathrm{min}$ is depicted in Figure 1. Two main distinct regions have been identified based on the material flow behaviour. These regions are a stirred (nugget) zone(SZ) and an interface between the SZ and the Base Material (BM) called the thermomechanically affected zone (TMAZ). For instance, these region scan be visualized through the distribution of secondary intermetallic phases (lighter areas) by means of backscattered electron (BSE) imaging, as shown in Figure 2(a-b). According to E.P. Silva et. al. ${ }^{11-13}$, these intermetallic compounds are those of Mg-Zn, Mg-Zn-RE and Mg-RE type with a total volume fraction of around $7.5 \%$. In the present case, the intermetallic compounds exist in all three zones i.e. BM, TMAZ and SZ, although their distribution differs. The BSE observations show that the rotation speed of $1200 \mathrm{rpm}$ resulted in generation of a basin-shaped stirring zone with a good degree of continuity. Besides that, a microstructure with small particles of intermetallic is formed and no defect is observed at the center section of the stirring zone. Also, the results show that the SZ exhibit a finely fragmented intermetallic structure (Figure 2(a)). These fragments appear to be partially pulverised within the $\alpha-\mathrm{Mg}$ matrix. On the other hand, a network of intermetallic compounds, mainly along the grain boundaries, is observed to form in the BM with a heterogeneous distribution (Figure 2 (b)) due to the mechanical beating during solidification ${ }^{11}$. In such a case, no dendrite growth of intermetallic phases has been observed i.e. the intermetallic compounds develop a globular form. The electron backscatter diffraction (EBSD) image of the BM (Figure 3(a)) and of the SZ (Figure 3(b)) shows a microstructure composed of fully recrystallized $\alpha-\mathrm{Mg}$ grains with a mean size of around 120 and $2-4 \mu \mathrm{m}$ respectively. Figure 4 revels that both thermal and plastic deformation effects take place in the TMAZ region. The TMAZ region is present on either side of the stir zone, which is larger in the retreating side than in the advancing side. This may be a result of the effect of low heat input in the retreating side during the processing. In this case, the strain rate applied to the retreating side within the welded joint is supposed to be lower than that at the advanced side, which certainly promotes such low deformation temperatures. The TMAZ region is composed of partially recrystallized $\alpha-\mathrm{Mg}$ grains, as well as a network of intergranular intermetallic compounds that were partly dissolved (less bright areas in Figure 2(a)) within the $\alpha-\mathrm{Mg}$ matrixdue to the temperature and pressure involved in the casting process ${ }^{11}$. Also, the $\alpha-\mathrm{Mg}$ grains have no dominant preferred orientation along the TMAZ region induced by stirring and likely lead to a less brittle weld, which contrasts with what is observed in the fusion weld. Another important observation is that an area with significant accumulation of intermetallic particles is observed to form between the SZ and the BM region in the advancing side, as depicted in Figure 5 (also indicated by the white arrow in Figure 1).It is plausible to assume that such phase segregation might be attributable to an inability to supply sufficient heat input during welding. In such case, 
if the heat produced by friction and stirring is sufficient to deform plastically the material around the rotating tool, it is possible to fabricate a continuous defect-free weld. The friction stir welded ZK60 alloy should be free from such microstructural (flow) defects since there is no melting taking place i.e. the heat input should not increase the peak temperature above that melting point. We have estimated the heat input generated by the FSW in the ZK60-RE casting alloy based on the Eq. 1 proposed by Wei et al. ${ }^{8}$

$$
H I=\frac{2 \pi \omega T}{1000 \nu}
$$

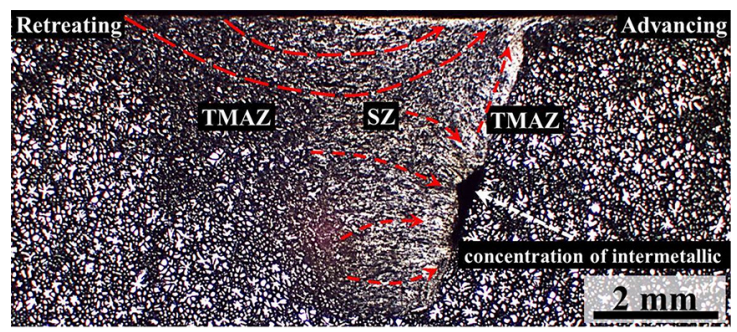

Figure 1. Macrograph of the cross-section of the FSW sample for the travel speed of $200 \mathrm{~mm} / \mathrm{min}$. The red arrows show the flow of material during processing. The indicated dark area is an intermetallic segregation region.
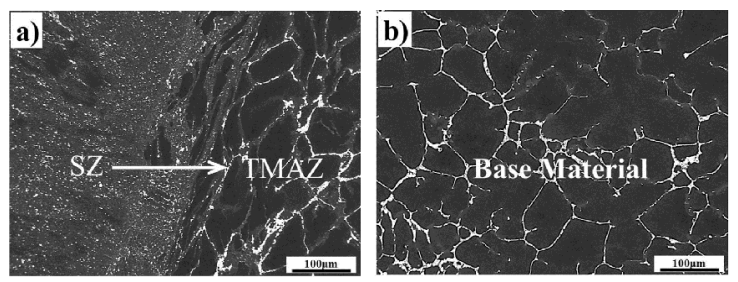

Figure 2. BSE image of (a) the interface between SZ and BM regions and (b) the base metal along the cross section welded ZK60-RE alloy at $200 \mathrm{~mm} / \mathrm{min}$.
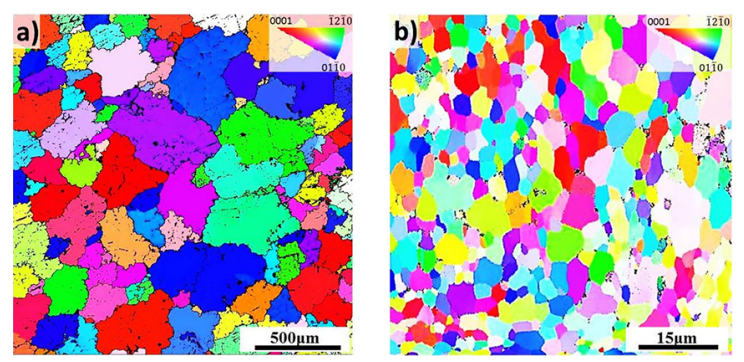

Figure 3. EBSD inverse pole figure map of the a) BM and b) SZ regions along the cross section welded ZK60-RE alloy at $200 \mathrm{~mm} / \mathrm{min}$.

where $\omega$ is the tool rotation [rpm], $T$ is the spindle torque [N.m] and $v$ is the welding speed [ $\mathrm{mm} / \mathrm{min}]$.

The heat input for the friction stir welded ZK60-RE casting alloy at a travel speed of $200 \mathrm{~mm} / \mathrm{min}$ is $378 \mathrm{~J} / \mathrm{mm}$, as shown in the graph of figure 6 . These results indicate that the resulting temperature generated by the heat input of 378 $\mathrm{J} / \mathrm{mm}$ is supposed to be insufficient for the welding process.
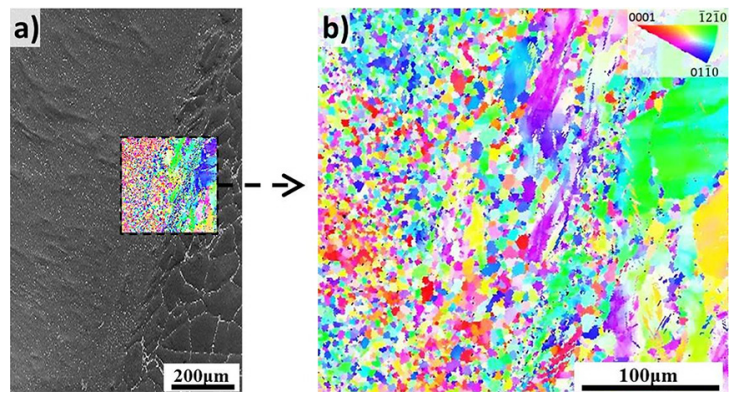

Figure 4. a) Low-magnification BSE image of the region from where the b) EBSD inverse pole figure map of the interface between SZ and $\mathrm{BM}$ regions was collected.

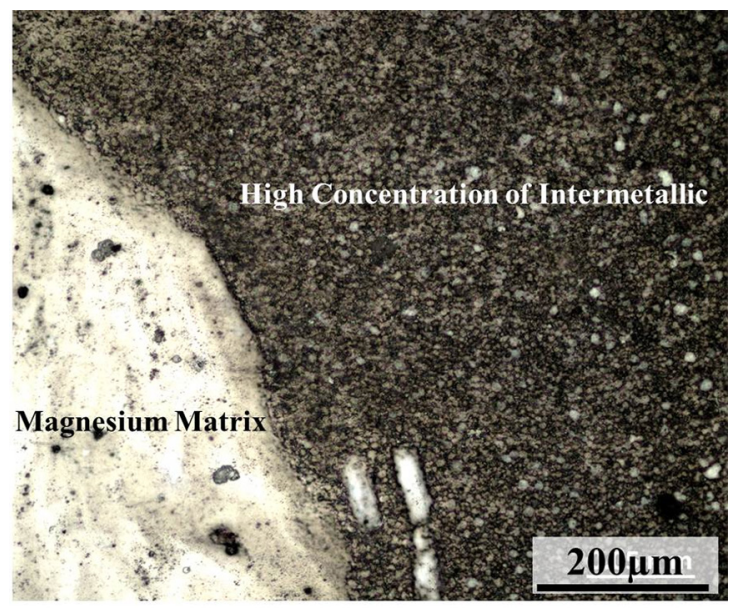

Figure 5. Optical micrograph of the region where the segregation of intermetallics is found in the friction stir welded ZK60-RE casting alloy.

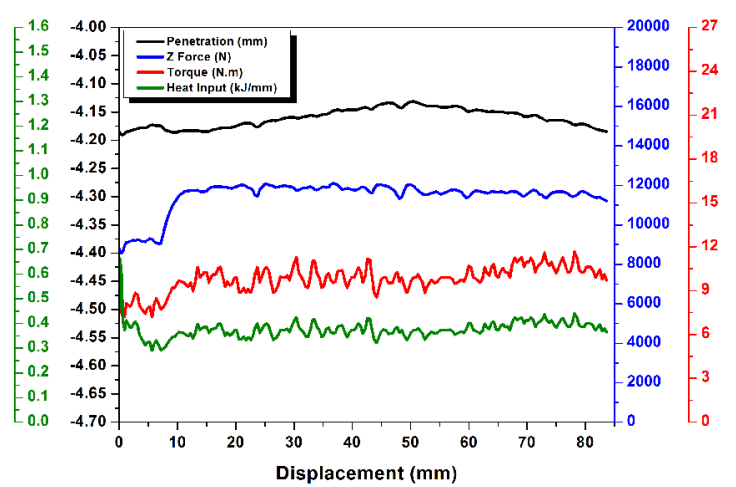

Figure 6. FSW parameters obtained for the ZK60-RE butt-joint at the rotation speed of $1200 \mathrm{rpm}$ and travel speed of $200 \mathrm{~mm} / \mathrm{min}$.

\subsection{Residual stress}

Figure 7 shows the results of the transversal stress profiles at the cross section of the friction stir welded ZK60-RE casting alloy at a travel speed of $200 \mathrm{~mm} / \mathrm{min}$. The (103), (112) and (201) diffraction lines are those used for the stress estimation. It can be seen that longitudinal stresses resulting 
from FSW are mostly of tensile nature under the shoulder region and comprise the SZ and the TMAZ turning into compression towards the base metals ${ }^{11,14}$. Also, it shows a symmetrical trend, which is similar to an " $M$ " shape and the maximum residual tensile stress occurring within the retreating side was $30 \mathrm{MPa}$. Allow compression occurs at the periphery of the shoulder at the advancing side. The main heat input during FSW is caused by the friction between the tool shoulder and the sample surface and by the material flow during welding ${ }^{15,16}$. Thus, the highest temperatures will be achieved at the edges of the shoulder due to the highest tangential speeds generated in this region. In addition, the higher the heat input, the higher the temperatures achieved during welding, and consequently, the higher the expansions and contractions during the welding. Although the peak temperature should be higher at the edge of the tool shoulder in the advancing side, the tensile stress is higher in the retreating side. This suggests that the cooling rate that rises with increasing temperatures promotes more rapid cooling of the advancing side down to room temperature. Thus, the increased tensile stress level at the retreating side may be explained by a last contraction of the retreating side at the end of the cooling process that imposes tensile stresses higher than in the advancing side.

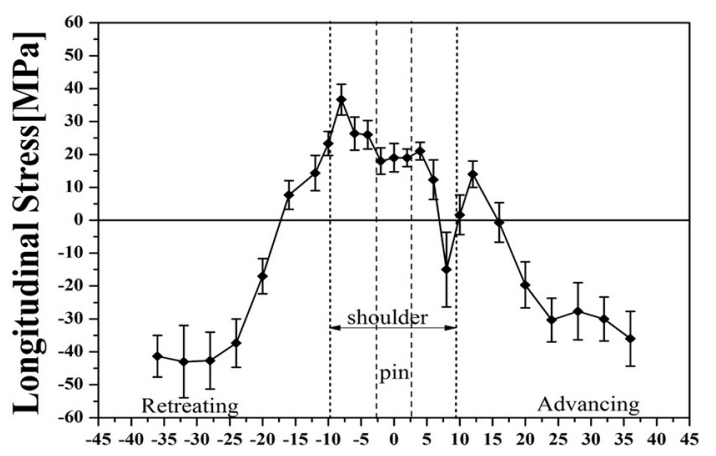

Distance from the weld centerline $[\mathrm{mm}]$

Figure 7. Longitudinal residual stress line profile along the crosssection of the friction stir welded ZK60-RE alloy at the rotation speed of $1200 \mathrm{rpm}$ and travel speed of $200 \mathrm{~mm} / \mathrm{min}$.

\section{Summary and Conclusions}

The effects of a travel speed of $200 \mathrm{~mm} / \mathrm{min}$ and a rotation speed of $1200 \mathrm{rpm}$ on the microstructure and residual stress of friction stir welded ZK60-RE casting alloy were investigated and the following conclusions could be drawn:

a) The feasibility of the FSW process to produce a defect-free butt joint in an as-cast ZK60-1.5RE magnesium alloy is achieved i.e. the tool rotation speed of $1200 \mathrm{rpm}$ has a good welding ability with the travel speed of $200 \mathrm{~mm} / \mathrm{min}$ and a tool shoulder diameter of $18 \mathrm{~mm}$.

b) The effective nature (defect-free) of the butt joint seems to be attributed to sufficient heat input during
FSW that would lead to less dendrite microstructures at the TMAZ. In this case, the heat input of $378 \mathrm{~J} /$ mm caused a substantial thermal contraction during welding leading to high levels of residual stress, which is of tensile and compressive nature for the region below the shoulder and the base material respectively.

c) The microstructure in SZ is super refined and fully recrystallized, unlike the TMAZ, where partial recrystallization and a deformed microstructure is observed. A sharp transition or preferred orientation is not observed.

d) The part of the profile corresponding to the zones of influence of the FSW (SZ, TMAZ) may be displayed on itself as a result of rotation of 180 degrees with respect to a point on the connection axis. A maximum tensile peak of approximately $30 \mathrm{MPa}$ in the retreating side and a compression peak of approximately -20MPa in the advancing side are observed at both contact edges between the tool shoulder and the plates. The residual stresses are due to gradients of thermal contraction and material flow across the stir zone.

\section{Acknowledgements}

The authors acknowledge the funding of FAPESP, processes 2010/11391-2, 2011/09324-8 and 2011/19218-0. Authors are thankful to Rima Group for supplying the raw materials used in magnesium alloy casting production and to the Brazilian Nanotechnology National Laboratory, Campinas-SP, Brazil, for providing the use of FSW facility. EPS also acknowledges FAPESP and CNPQ for the scholarships. HP is CNPq fellow. Authors are also grateful for the important assistance of Katja Angenendt and Monika Nellessen (Max-Planck Institut fuer Eisenforschung, Germany) with EBSD measurements.

\section{References}

1. Pekguleryuz M, Kainer K, Kaya A. Fundamentals of Magnesium Alloy Metallurgy. Cambridge: Woodhead; 2013.

2. Ma C, Liu M, Wu G, Ding W, Zhu Y. Tensile properties of extruded ZK60-RE alloys. Materials Science and Engineering: A. 2003;349(1-2):207-212.

3. Zhou HT, Zhang ZD, Liu CM, Wang QW. Effect of Nd and Y on the microstructure and mechanical properties of ZK60 alloy. Materials Science and Engineering: A. 2007;445-446:1-6.

4. Leontis TE. Magnesium and magnesium alloys - The Room and Elevated Temperature Properties of Some Sand Cast Magnesium-Base Alloys Containing Zinc. Transactions of the Metallurgical Society of AIME. 1949;185:327.

5. Lagowski B. Effects of composition and heat treatment on the tensile properties of $\mathrm{ZE} 41(\mathrm{Mg}-4 \mathrm{Zn}-1 \mathrm{RE}-0.7 \mathrm{Zr})$ casting alloy. Transactions of the American Foundrymen's Society. 1977;85:237-240. 
6. Mishra RS, Ma ZY. Friction stir welding and processing. Materials Science and Engineering: R: Reports. 2005;50(1-2):1-78.

7. Campbell FC Jr. Manufacturing Technology for Aerospace Structural Materials. Amsterdam: Elsevier Science; 2006. $616 \mathrm{p}$.

8. Wei LY, Nelson TW. Correlation of microstructures and process variables in FSW HSLA-65 steel. Welding Journal. 2011;90:95-101.

9. Noyan C, Ismail C, Jerome B. Residual Stress: Measurement by Diffraction and Interpretation. New York: Springer; 2013.

10. Welzel U, Ligot J, Lamparter P, Vermeulen AC, Mittemeijer EJ. Stress analysis of polycrystalline thin films and surface regions by X-ray diffraction. Journal of Applied Crystallography. 2005;38:1-29.

11. Silva EP, Batista LF, Callegari B, Feierabend I, Buzolin RH, Coelho RS, et al. Casting in the semi-solid state of ZK60 magnesium alloy modified with rare earth addition. Advanced Materials Research. 2014;922:694-699.

12. Silva EP, Buzolin RH, Callegari B, Warchomicka F, Requena GC, Pinto HC. Effect of mischmetal additions and solution heat treatments (T4) on the microstructure and mechanical properties of thixocast ZK60-RE magnesium alloys. Materials Science Forum. 2016;879:2300-2305.

13. Silva EP, Batista LF, Callegari B, Buzolin RH, Warchomicka $\mathrm{F}$, Requena GC, et al. Solution and ageing heat treatments of ZK60 magnesium alloys with rare earth additions produced by semi-solid casting. Materials Research. 2014;17(6):1507-1512.

14. Lima EBF, Wegener J, Dalle Donne C, Goerigk G, Wroblewski T, Buslaps T, et al. Dependence of the microstructure, residual stresses and texture of AA 6013 friction stir welds on the welding process. Zeitschrift für Metallkunde. 2003;94(8):908-915.

15. Threadgill PL, Leonard AJ, Shercliff HR, Withers PJ. Friction stir welding of aluminium alloys. International Materials Reviews. 2009;54(2):49-93.

16. Silva EP, Batista LF, Callegari B, Pereira R, Buzolin RH, Coelho RS, et al. Microstructure and Residual Stress Formation during Friction-Stir Welding of Semi-Solid Cast ZK60-RE Magnesium Alloy. Advanced Materials Research. 2014;922:688-693. 